\title{
The Role of Signal Transducer and Activator of Transcription 3 (STAT3) in Tumor Immunity
}

\author{
Oeij Anindita Adhika ${ }^{1 *}$ and M. Nurhalim Shahib²
}

\begin{abstract}
${ }^{1}$ Post Graduate Program in Medical Science, Padjadjaran University, Jl. Eijkman No. 38, Bandung, Indonesia ${ }^{2}$ Faculty of Phamarmacy, Padjadjaran University, Jl. Raya Bandung Sumedang Km. 21, Bandung, Jatinangor, Indonesia *e-mail: anindita_adhika@yahoo.com
\end{abstract}

\section{Abstract}

$\mathrm{B}$ ACKGROUND: Inflammation is a key component of the tumor microenvironment.Cancer-associated inflammation is marked by the presence of specific inflammatory cells and inflammatory mediators. Moreover, immune cells in the tumor microenvironment not only fail to mount an effective antitumor immune response, but also interact intimately with the tumor cells to actively promote oncogenesis.

CONTENT: Their roles in regulating cytokine-dependent inflammation and immunity make the signal transducer and activator of transcription (STAT) proteins critical players in determining whether immune responses in tumor microenvironment promote or inhibit cancer. Recent evidence suggests a crucial role for STAT family proteins, especially STAT3 (signal transducer and activator of transcription 3), which is a point of convergence for numerous oncogenic signaling pathways, in selectively inducing and maintaining a procarcinogenic inflammatory microenvironment, both at the initiation of malignant transformation and during cancer progression. The persistent activation of STAT3 increases tumor cell proliferation, survival, and invasion while suppressing antitumor immunity.

SUMMARY: STAT3 signaling pathway constitutes a potential preventive and therapeutic target for cancer immunotherapy.

\section{Abstrak}

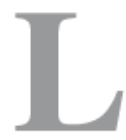

ATAR BELAKANG: Inflamasi merupakan komponen yang sangat penting dalam tumor microenvironment. Cancer-associated inflammation ditandai oleh kehadiran sel inflamasi dan mediator inflamasi yang spesifik. Lebih jauh, sel imun dalam tumor microenvironment tidak hanya gagal dalam memberikan respon imun antitumor yang efektif, bahkan sebaliknya berinteraksi erat dengan sel tumor untuk mempromosikan onkogenesis secara aktif.

ISI: Peranan protein signal transducer and activator of transcription (STAT) dalam meregulasi inflamasi dan imunitas yang bergantung pada sitokin menjadikannya pemain penting dalam menentukan apakah respon imun dalam tumor microenvironment mempromosikan atau menginhibisi kanker. Bukti baru-baru ini mendukung peranan krusial protein famili STAT, khususnya STAT3 (signal transducer and activator of transcription 3), yang mana merupakan titik pertemuan untuk beberapa jalur oncogenic signaling, dalam menginduksi dan mempertahankan secara selektif microenvironment inflamasi prokarsinogenik, baik pada inisiasi transformasi keganasan maupun pada progres kanker. Aktivasi persisten STAT3 meningkatkan proliferasi dan survival sel tumor, seraya menekan imunitas antitumor.

RINGKASAN: STAT3 signaling pathway merupakan target preventif dan terapeutik yang potensial untuk imunoterapi kanker. 
KEYWORDS: STAT3, inflammation, tumor microenvironment, cancer immunotherapy

Indones Biomed J 2012; 4 (3): 143-150
KATA KUNCI: STAT3, inflamasi, tumor microenvironment, imunoterapi kanker

Indones Biomed J 2012; 4 (3): 143-150

\section{Introduction}

The immune system has been called a double edge sword because of its ability to fight infectious pathogens on the one hand and to produce autoimmunity on the other. Similarly, it can be said that the immune system serves both as a tumor suppressor and as initiator and/or a promoter of tumors $(1,2)$. Thus, the immune system can promote the elimination of tumors, but often the immune responses are modulated or suppressed by the tumor microenvironment (3).

Major conceptual and technical advances in immunology over the past 25 years have led to new understanding of cellular and molecular interplays between the immune system and tumor (4). The paucity of immunological danger signals necessary for immune activation, the increased concentration of immunosuppressive factors and the accumulation of immunosuppressive cells in the tumor microenvironment indicate that immune regulation has an active role in cancer progression (5). Immune cells that infiltrate tumors engage in an extensive and dynamic crosstalk with cancer cells (6).

Inflammation is a crucial function of the innate immune system that protects against pathogens and initiates specific immunity (1). Growing evidence has suggested that tumors are sustained and promoted by inflammatory signals from the surrounding microenvironment (7-10). Inflammatory responses play decisive roles at different stages of tumor development including initiation, promotion, malignant conversion, invasion, and metastasis. Inflammation also affects the immune surveillance and responses to therapy. Therefore, inflammation is now recognized to be important in the pathogenesis of many types of malignancies. Clinical and epidemiological studies on chronic inflammatory conditions at specific organ sites have provided some of the most compelling evidence that inflammation promotes malignant transformation. Virtually, all liver and gastric cancers arise from infections that cause chronic hepatitis and chronic gastritis, respectively. Moreover, Crohn's disease and ulcerative colitis are associated with increased incidence of colon cancer. Consequently, inflammation should be considered as a valuable target for cancer prevention and therapy (10-12).

Colon cancer represents a paradigm for the connection between inflammation and cancer in terms of epidemiology and mechanistic studies in preclinical models. Preclinical models of colitis-associated cancer (CAC) have provided an invaluable tool for dissecting the mechanistic basis of cancer-related inflammation (13). Moreover, during the past 10 years genetic studies using cell-specific knockout animals have facilitated researchers to start unraveling the molecular mechanism that links inflammation with cancer. Results of the observations suggest that both the extrinsic and intrinsic pathways underlying cancer inflammation link cancer and inflammation. The studies have also led to the idea that the tumor microenvironment is as important as the tumor cell population, thus inflammatory microenvironment has been suggested as the seventh hallmark of cancer (14).

Genetic evidence indicates that the transcription factors of nuclear factor- $x \mathrm{~B}(\mathrm{NF}-\boldsymbol{x} \mathrm{B})$ and signal transducer and activator of transcription 3 (STAT3) have a central role in this context by regulating distinct functions in cancer cells and surrounding non-tumorigenic cells. A causal link between chronic inflammation and the development of cancer has long been recognized, and substantial insight into the underlying molecular mechanisms has been obtained in recent years. A large body of evidence suggests that STAT3 is one of the few key regulatory signaling molecules whose aberrant activation is invariably associated with inflammation and cancer, but only very little genetic evidence available as yet that confirms such a role of STAT3 (13). 


\section{Signal Transducer and Activator of Transcription}

The STAT protein family was originally discovered in the course of studies of their capacity to mediate signaling from IFN and IL-6 receptors following engagement with their cognate cytokines (15). Signal transducer and activator of transcription 3 (STAT3) belong to STAT family of proteins, which are both signal transducers and transcription factors. Up to now seven members in this family have been identified, namely STAT1, STAT2, STAT3, STAT4, STAT5A, STAT5B, and STAT6, which are respectively encoded by distinct genes $(16,17)$. Alternative splicing gives rise to truncated forms of some of the STAT proteins such as STAT $1 \beta$ and STAT $3 \beta$, which are splice variants of the wild type, full length STAT1 and STAT3 proteins, with deletions of the C-terminal domains (16).

Structurally, STAT proteins have the following distinct domains: the N-terminal, coiled-coil, DNA binding, the Linker, Src-homology 2 (SH2), and C-terminal transactivation domains. Each of these domains has a distinct function: the $\mathrm{N}$-terminal domain is important in STAT dimer-dimer interactions; the DNA binding domain forms complexes between STAT proteins and DNA; the $\mathrm{SH} 2$ domain engages in dimerization between two activated STAT monomers through reciprocal phospho-tyrosine (pTyr)-SH2-domain interactions, while the C-terminal portion of the protein functions as the transcriptional activation domain. The STAT proteins are differentially activated in a context-dependent manner in response to growth factors, cytokines, or other polypeptide ligands. They have important roles in fundamental processes including proliferation, development, differentiation, inflammation, and apoptosis (Table 1) $(16,17)$.

STATs activation is initiated by the phosphorylation on a critical tyrosyl residue. In normal cell and under normal biological conditions, STATs activation is rapid and transient $(5,16,17)$ because they are negatively regulated by cytokine-inducible SH2-containing (CIS) protein or suppressor of cytokine signaling protein (SOCS1 and SOCS-3), Jak binding protein (JAB), STAT-induced STAT inhibitor, and protein inhibitors of activated STATs (PIAS) $(5,16)$.

STATs are activated by many growth factor receptors with intrinsic tyrosine-kinase activity. However, cytokine receptors do not usually have intrinsic tyrosine kinase activity; instead, their engagement activates receptorassociated tyrosine kinases, most prominently the Janus kinase (JAK) family kinases (JAK1, JAK2, JAK3, and

\section{Table 1. STAT family activation by specific cytokines and growth factors, and their target genes (Yu et al.17)}

\begin{tabular}{|c|c|c|c|}
\hline STAT protein & Key activators & Main target genes & Example genes \\
\hline STAT1 & IFNY, IFNa and IFN $\beta$ & $\begin{array}{l}\mathrm{T}_{H} \text { 1-type immunostimulatory, } \\
\text { and proapoptosis }\end{array}$ & $\begin{array}{l}\text { TBX21, CD80, CD40, IL-12, } \\
\text { CDKN1A and several caspases }\end{array}$ \\
\hline STAT2 & IFNa and IFN $\beta$ & $\begin{array}{l}\mathrm{T}_{\mathrm{H}} \text { 1-type immunostimulatory, } \\
\text { and proapoptosis }\end{array}$ & $C D 80$ and $C D 40$ \\
\hline STAT3 & $\begin{array}{l}\text { IL-6, IL-10, IL-23, } \\
\text { IL-21, IL-11, LIF and OSM }\end{array}$ & $\begin{array}{l}T_{H} \text { 17-type, anti-apoptosis, } \\
\text { pro-proliferation, angiogenic, } \\
\text { and metastatic }\end{array}$ & $\begin{array}{l}\text { IL-17, IL-23, BCl- } X_{L}, B C l-2, \\
M c l-1, C C N D 1 \text { and VEGF }\end{array}$ \\
\hline STAT4 & IL-12 & $\mathrm{T}_{H}$ 1-type, especially IFNY & IFNY \\
\hline $\begin{array}{l}\text { STAT5A and } \\
\text { STAT5B }\end{array}$ & $\begin{array}{l}\text { IL-2, GM-CSF, IL-15, IL-7, } \\
\text { IL-3, IL-5, growth hormones } \\
\text { and prolactin }\end{array}$ & $\begin{array}{l}\text { Anti-apoptosis, pro-proliferation, } \\
\text { and differentiation }\end{array}$ & $B C L-X, C C N D 2$ and FOXP3 \\
\hline STAT6 & IL-4 and IL-13 & $\mathrm{T}_{\mathrm{H}}$ 2-type, and anti-apoptosis, & GATA3 and BCL-2 \\
\hline
\end{tabular}


TYK2) $(5,16,17)$. Following phosphorylation of specific tyrosine residues in STAT proteins, they form stable homodimers or heterodimers with other STAT proteins through reciprocal pTyr-SH2 domain interactions. Importantly, many of the downstream target genes of STATs encode cytokines and growth factors, the receptors of which signal through the same STATs, thereby providing a mechanism for autocrine and paracrine STAT activation. For example, in response to IL-6 signaling through gp130-JAK, STAT3 forms homodimers that translocate to the nucleus. In the nucleus STAT3-STAT3 homodimers modulate the expression of genes encoding IL-6 itself and other mediators crucial for the classic physiological acute phase response and cancer-promoting inflammatory conditions $(10,17,18)$. By contrast, on stimulation by type 1 IFNs, STAT1-STAT1 homodimers or STAT1-STAT2 heterodimers accumulate in the nucleus and regulate the expression of genes that promote growth arrest and apoptosis. Type 1 IFNs also activate certain types of innate immunity, including natural killer cell responses, as well as $\mathrm{T}_{\mathrm{H}} 1$-type adaptive immunity, which is characterized by the production of IFN $\gamma$, the receptor of which further activates STAT1 and STAT2. This loop is crucial for controlling viral infection and mediating antitumor immunity (17).

STAT3 was first described as a DNA-binding activity from IL-6-stimulated hepatocytes, capable of selectively interacting with an enhancer element in the promoter of acute-phase genes, known as the acute-phase response element $(15,17)$. The gene that encodes STAT3 is located on chromosome $17 \mathrm{q} 21$, and it encodes a $92-\mathrm{kD}$ protein (19). When first discovered, STAT3 appeared to be a straightforward additional member of the growing STAT family that would function in the induction of a limited set of target genes in response to IL-6 released during inflammation $(15,16)$.

The growth factor receptors known to activate STAT3 include EGFR (epidermal growth factor receptor) and HER2 (human epidermal growth factor receptor 2), FGFR (fibroblast growth factor receptor), IGFR (insulinlike growth factor receptor), HGFR (hepatocyte growth factor receptor), PDGFR (platelet-derived growth factor receptor) and VEGFR (vascular endothelial growth factor receptor) (5). The list of its possible functions grew through subsequent studies in cell culture, showing that it is activated in a wide variety of signaling systems and mediates a bewildering complexity of responses (15). However, aberrant activation of certain STAT proteins, particularly STAT3 and STAT5, is associated with many human cancers. Constitutive activation of STAT3 has been found in a wide spectrum of human malignancies $(16,17)$.

\section{STAT3 and Tumorigenesis}

A decade ago Hanahan and Weinberg suggested that the malignant growth characteristics of cancer cells required six essential alterations in cellular physiology, namely self-sufficiency in growth signals, insensitivity to growth inhibiting signals, evasion of apoptosis, unlimited cellular replication, sustained angiogenesis, and tissue invasion and metastasis (20). Aberrant activation of STAT3, which is involved in signaling through the IL-6 receptor, has been shown to inhibit inflammatory responses and crosstalk between innate and adaptive immune responses in various human cancers (18). STAT3 promotes at least three of these hallmarks, namely proliferation, survival, and angiogenesis and often more when investigated in specific cell types $(10,19)$.

STAT3 inhibits apoptosis by upregulating the prosurvival Bcl-2 proteins Bcl-XL, Mcl-1, and Bcl-w. In epithelial cells, STAT3 also induces other proteins that indirectly suppress apoptosis, including Hsp70 and the C-type lectin-type RegIII $\beta$, which both are overexpressed in human colon cancer and inflammatory bowel disease. In conjunction with c-jun, STAT3 inhibits the extrinsic apoptosis pathways through transcriptional repression of the FAS death receptor. STAT3-mediated induction of survivin not only suppresses apoptosis, but also promotes mitogenic progression through binding to cdc2. However, STAT3 promotes proliferation primarily by stimulating transcription of cyclin B1, cdc2,c-myc, and cyclin D1, along with the induction of $c$-jun and $c$-fos and repression of the cell cycle inhibitor $p 21$. Accordingly, STAT3 promotes the $\mathrm{G} 1 / \mathrm{S}$ phase transition of the cell cycle in gastric, colon, and squamous cell carcinomas as well as in bladder cancer cells. In contrast, STAT3 ablation in intestinal epithelium in vivo or in tumor cell lines in vitro resulted in cell cycle arrest in the G2/M transition and is associated with histone $\mathrm{H} 3$ phosphorylation-associated mitotic arrest $(5,10,16,19,21)$.

Activated STAT3 can also induce NF- $\varkappa$ B p100 to process to $\mathrm{p} 52$, which subsequently inhibits apoptosis of cancer cells. Moreover, it has been shown that STAT3 represses the $\mathrm{p} 53$ gen transcription rate by binding to $\mathrm{p} 53$ promoter and subsequently affecting p53-mediated tumor cell apoptosis (19).

The role of STAT3 in angiogenesis was first evidenced when VEGF was found to be a direct target of STAT3 in mouse melanoma cells, and this was further confirmed by a study on a human pancreatic cancer system $(16,19)$. It is also known that nuclear STAT3 correlates with enhanced 


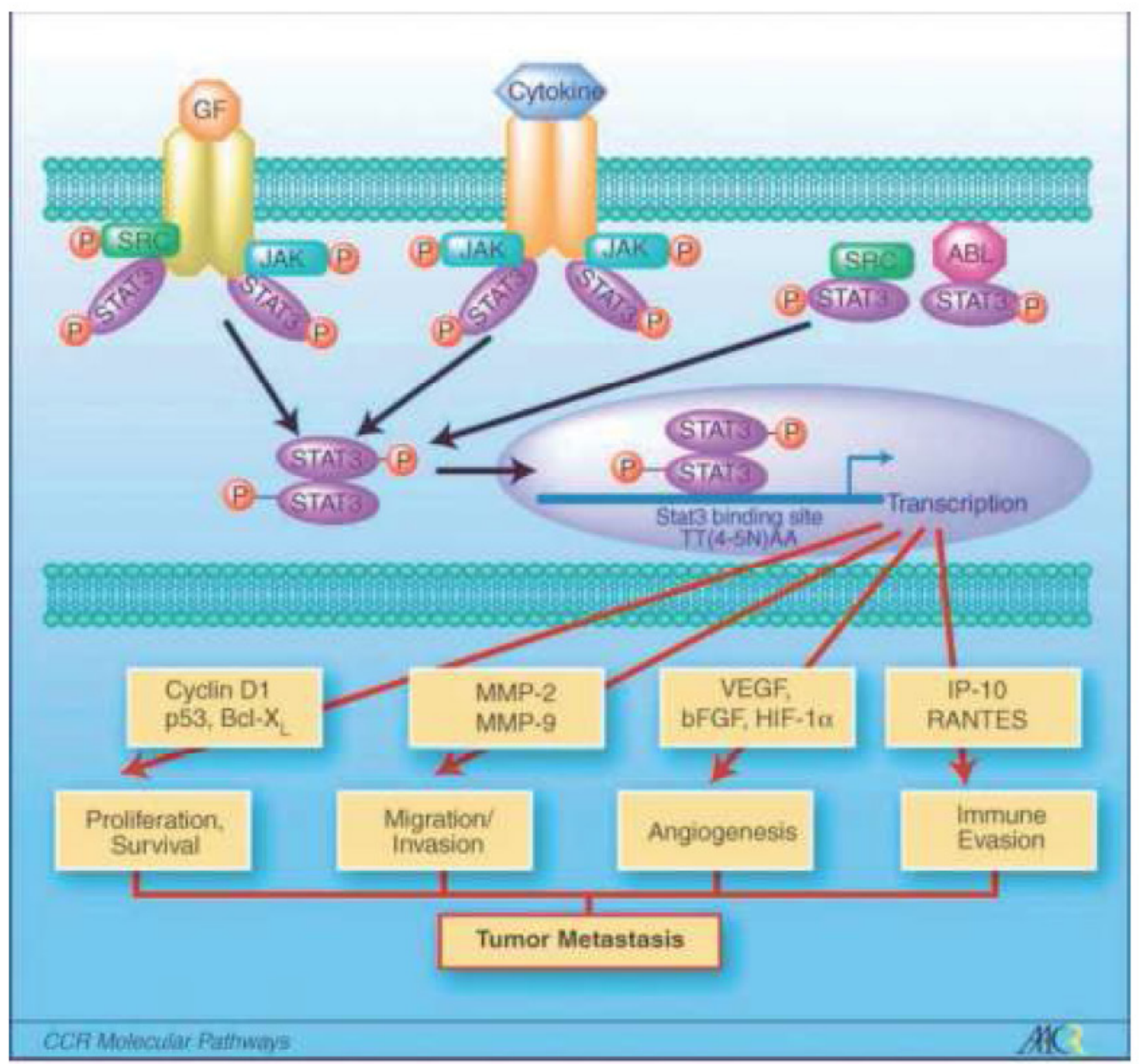

Figure 1. Contribution of STAT3 signaling pathway to cancer metastasis (Adapted with permission from Huang. AACR, 2007).

VEGF expression and microvessel density in gastric cancer (10). STAT3 regulates the transcription of VEGF indirectly by controlling the expression of HIF-1 $\alpha$ (hypoxiainducible factor-1 alpha), a key inducible transcription factor for the $V E G F$ gene. Several studies have shown that STAT3 regulates the expression of other angiogenic molecules such as bFGF (basic fibroblast growth factor), which participates in angiogenesis by inducing the migration, proliferation, and differentiation of endothelial cells and by regulating VEGF expression in tumor cells $(5,16,19,22)$. Furthermore, it has been shown that STAT3 can be activated by bFGF and VEGF upon binding of these molecules to their receptors and transducing the receptor signals in endothelial cells. Consequently, STAT3 activation is necessary for endothelial cell proliferation, migration, and microvascular tube formation $(16,19,22)$.

Other evidence also suggests that STAT3 transcriptionally activates the expression of genes that promote tumor cell migration and invasion. Specifically, activated STAT3 regulates tumor invasion of melanoma cells by regulating the gene transcription of matrix metalloproteinase 2 (MMP-2). STAT3 activation increases migration and invasion of bladder cancer cells by induction of MMP-1 and MMP-10 and is also required for induction of MMP-9 in transformed human mammary epithelial cells $(10,19)$. Moreover, STAT3 may contribute to tumor cell migration and invasion through transcriptionindependent pathways. STAT3 protein in ovarian cancer cells has been found to localize to focal adhesions along with focal adhesion kinases and paxillin, subsequently modulating the invasiveness of the cells (19).

Most recent studies have shown unambiguously that STAT3 signaling plays a pivotal role in the regulation of tumor immunity. Constitutively activated STAT3 in both tumor cells and tumor-associated immune cells inhibits the expression of inflammatory cytokines and chemokines 
that activate antitumor innate and adaptive immunity, such as IFN- $\beta$, TNF- $\alpha$, IL-6, regulated upon activation/normal T-cell expressed and secreted, and IFN- $\gamma$-inducible protein-10. STAT3 signaling in tumors also promotes the expression of some factors such as VEGF and IL-10 that inhibit dendritic cell maturation and T-cell activation, giving rise to immune tolerance $(5,19)$. Blockade of STAT3 signaling in tumors reverses these negative effects resulting in enhanced innate immunity and activation of dendritic cells, which leads to tumor-specific T-cell responses. Ablation of STAT3 in the immune cells of tumor-bearing hosts elicits multicomponent antitumor immunity that inhibits tumor growth, including dendritic cells, T cells, natural killer cells, and neutrophils (19).

Ablating STAT3 gene in natural killer cells and macrophages in mice can boost expression of TH1 mediators, leading to STAT1 upregulation and increased antitumor immune responses. Both type 1 interferons and IFN $\gamma$ mediate antitumor immunity through STAT1dependent innate effectors, TH1-type responses, and cytotoxic T lymphocyte activation. The ability of STAT3 to antagonize STAT1 has been well documented (17).

\section{STAT3 and Metastasis}

Metastasis is the major cause of death in most cancer patients $(6,19,20)$. The process of metastasis is complex and requires multiple steps. Recent studies unambiguously show that metastasis requires close collaboration between cancer cells, immune and inflammatory cells, and stromal elements. The first step is represented by epithelialmesenchymal transition, in which cancer cells acquire fibroblastoid characteristics that increase their motility and allow them to invade epithelial linings/basal membranes and reach efferent blood vessels or lymphatics. Loss of E-cadherin expression is envisioned as a key event in the epithelial-mesenchymal transition. In the second step, cancer cells intravasate into blood vessels and lymphatics (23). Inflammation may promote this through production of mediators that increase vascular permeability. This is followed by the third step, in which metastasis-initiating cells survive and travel throughout the circulation. It is estimated that only about $0.01 \%$ of cancer cells that enter the circulation eventually survive and give rise to micrometastasis (24). Next, integrin-mediated arrest allows the extravasation of circulating cancer cells. Finally, single metastatic progenitors interact with the immune, inflammatory, and stromal cells and start to proliferate (25). In general, the molecular mechanisms that control the steps of metastasis are related to alterations of various oncogenes, tumor suppressor genes, metastasis suppressor genes, and growth factors and their receptors. STAT3 is known to be activated by numerous cytokines, growth factors, and oncogenic proteins, including EGF, PDGF, VEGF, bFGF, IL-6, Src, and Ras, suggesting that STAT3 signaling may be one of the common pathways involved in regulating cancer metastasis (Figure1) (19).

Several lines of evidence indicate that the constitutive activation of STAT3 influences metastasis. The level of activated STAT3 protein is associated with metastasis in various types of tumors. For example, activation of STAT3 in thymic epithelial tumors, colorectal adenocarcinoma, and cutaneous squamous cell carcinoma correlates with lymph node metastasis. A study using an orthotropic pancreatic tumor animal model showed that blockade of activated STAT3 via ectopic expression of dominant-negative STAT3 significantly suppressed VEGF expression, angiogenesis, and liver metastasis of pancreatic tumor cells. Blocking of STAT3 signaling in highly metastatic melanoma cells significantly suppresses the expression of $M M P-2$ gene and invasiveness of the tumor cells and prevents lung metastasis in a mouse melanoma model. Blocking of STAT3 activation also suppresses brain metastasis of human melanoma cells in a brain metastasis animal model. Conversely, enforcing the expression of a constitutively activated STAT3 protein poorly converts metastatic melanoma cells into highly metastatic brain tumor cells in the model. The mechanism that promotes brain metastasis by STAT3 might be attributable to overexpression of bFGF, MMP-2, and VEGF caused by STAT3 activation, hence increasing tumor invasion and angiogenesis. Further implication of STAT3 in tumor metastasis is evidenced by the finding that elimination of STAT3 protein by RNA interference in mouse breast cancer cells can block expression of metastatic regulator Twist and prevent metastasis of breast cancer cells (19). Furthermore, a mechanism through which proinflammatory cytokines can affect the epithelialmesenchymal transition is via STAT3-mediated induction of Twist transcription (17). Collectively, these studies provide evidence that the STAT3 signaling pathway may affect tumor metastasis via regulation of the multiple steps of its process (19). 


\section{STAT3 and Cancer Immunotherapy}

Recent advances in the investigation of the role of STAT3 in tumor metastasis indicate that STAT3 signaling might be a common molecular target for blocking metastasis in human tumors. Several strategies have been pursued for developing inhibitors of STAT3, based on the complex nature of its gene expression and activity. Strategies to abolish STAT3 expression include the delivery of antisense oligonucleotides and small interfering RNA, whereas approaches to inhibition of STAT3 activity include the use of tyrosine kinase inhibitors, phosphopeptides, G-quartet oligodeoxynucleotides, decoy oligonucleotides, and small-molecule compounds that inhibit DNA-binding $(10,16,17,19,26)$.

Among these strategies against STAT3 is the use of small molecule inhibitors such as JSI-124 (cucurbitacin I), WP1066, STA-21, and IS3-295, which have the most immediate therapeutic potential $(10,16,19)$. JSI-124 has been identified in the National Cancer Institute Diversity Set as an inhibitor of JAK-2/STAT3, with no apparent effect on the Akt, extracellular signal-regulated kinase, or c-Jun NH2-terminal kinase pathways. JSI-124 is reported to inhibit cellular proliferation and induce apoptosis of multiple cancer cell lines in vitro as well as to inhibit tumor growth of A549 lung adenocarcinoma and MDAMB-468 breast cancer cells in nude mice. WP1066, another JAK-2 inhibitor, has been shown to suppress the growth of malignant glioma U87-MG and U373MG cells in vitro and in vivo. STA-21 shows remarkable inhibition of STAT3 dimerization, DNA binding, STAT3dependent luciferase activity, and nucleus translocation. Moreover, STA-21 reduces the growth and survival of breast cancer cells with constitutively activated STAT3 in vitro. IS3-295, a novel platinum (IV) compound, has also been identified in the National Cancer Institute Diversity Set as a selective STAT3 inhibitor. It interacts with STAT3 directly and inhibits STAT3 binding to specific DNA response elements. Unlike its prototype (cisplatin), IS3-295 has no effects on Akt and mitogenactivated protein kinase family pathways. IS3-295 inhibits STAT3-regulated genes cyclin $D 1, B c l-X_{L}$, and $V E G F$. It also blocks cell cycle progression and proliferation and mediated apoptosis of malignant cells in vitro (19). A new molecule IS3-201 has recently been identified that disrupts STAT3 dimerization. The evaluation of S3I-M2001 and S3I-201 in both cell-based studies and xenografts models of human breast tumors show potent antitumor activities (16). Lin et al. developed FLLL32, a novel curcumin- derived small molecule inhibitors of the JAK2/STAT3 pathway. FLLL32 has been shown to selectively inhibit STAT3 phosphorylation, STAT3 DNA binding activities, cell viability, and induce apoptosis in multiple myeloma, glioblastoma, colorectal and hepatocellular carcinoma cancer cells with constitutively activated STAT3 signaling (26). These studies represent a significant advance in the development of small molecules that target STAT3 as therapeutic against tumors (19). Consistent with the role of STAT3 in preventing apoptosis, the combination of STAT3 inhibitors and chemotherapy sensitizes cancer cells to apoptosis, thus suggesting the potential use of small molecule inhibitors of STAT3 as chemo-sensitizers (16).

STAT3-specific inhibitors have not yet been used much in clinical trials, although other drugs that can indirectly inhibit STAT3 activation, such as Atiprimod and gefitinib, have undergone clinical testing. At this point, based on the evidence from studies using relevant animal models, it might be expected that STAT3 inhibitors would have limited toxicity in normal cells because STAT3 activation in normal cells is transient and tightly controlled, and normal cells are not dependent on aberrant STAT3 activation for growth and survival. Indeed, primary embryo fibroblasts from conditional knockout mice lacking STAT3 proliferate similarly to their wildtype counterparts and display similar survival. However, despite the pivotal role of STAT3 during embryonic development, STAT3 has only mild effects of conditional ablation in adult tissues. STAT3 inhibitors reduce the survival of tumor cells with constitutive STAT3 signaling, but have minimal effect on the cells in which constitutive STAT3 signaling is absent. However, in spite of these optimistic data, it is noteworthy that recent studies have indicated that STAT3 activation promotes cardiomyocyte survival and cardiac angiogenesis in response to various pathophysiologic stimuli, thereby protecting the heart from injury and failure. In this regard, STAT3 inhibitors may cause side effects in patients with cardiac problems. Thus, the toxicity and side effects of STAT3 inhibitors must be thoroughly investigated in animal models and ultimately in clinical trials, with careful assessment as to whether the potential benefits far outweigh the associated risks to patients (19). Nevertheless, given the critical role of STAT3 activity in regulating the multiple steps of the metastasis process, targeting of STAT3 activation may prove to be a more effective approach to controlling metastasis than merely targeting individual molecules, such as VEGF and MMP-2. Thus, targeting of STAT3 signaling may represent a novel approach to controlling cancer metastasis $(10,19)$. 


\section{Conclusions}

Although the importance of the effects of cancer on the immune system has long been recognized, the molecular basis for the link between tumor and immune cells remains largely unknown. Recent studies have unraveled the underlying mechanisms by which chronic inflammation promotes many human cancers, and also identified STAT3 which is an important oncogenic signaling molecule that mediates the bidirectional communication.

Aberrant and persistent STAT3 activation is a frequent observation in human cancers of epithelial origin and is often associated with poor outcome. In cancer cells STAT3 is frequently activated, which promotes the expression of factors that are both immunosuppressive and STAT3 activating. These tumor-derived factors, in turn, upregulate STAT3 signaling in various immune cells subsets in the tumor microenvironment, which produce more immunosuppressive factors and abrogating the function of various immune effector cells. Many of these factors are also growth and angiogenic factors, which directly stimulate tumor-cell proliferation and surviva, and indirectly promote tumor progression through angiogenesis and metastasis. The constitutive activation of STAT3 both in tumor cells and in diverse immune cells in the tumor stroma also inhibits the expression of numerous factors and molecules necessary for immunemediated tumor rejection.

The ability of STAT3 to broadly and profoundly affect tumor immunity strongly indicates that constitutively activated STAT3 both in tumor cells and in tumor stromal immune cells is a promising target for cancer immunotherapy. Several important studies have provided convincing evidence supporting the concept of potential antitumor effects of inhibition of aberrant STAT3 activity in both cell culture and whole animal models for a variety of human tumors. Several studies to determine the impact on normal cells have also shown a slow down of growth of normal cells without significant apoptosis. A comprehensive understanding of the STAT3 signaling cascade is highly required to identify and validate the therapeutic targets that can simultaneously restrict the effect of tumor promoting inflammation and restore anti tumor immunity.

\section{References:}

1. Balkwill F, Charles KA, Mantovani A. Smoldering and polarized inflammation in the initiation and promotion of malignant disease. Cancer Cell. 2005; 7: 211-7.

2. Tesniere A, Schlemmer F, Boige V, Kepp O, Martins I, Ghiringhelli F, et al. Immunologic death of colon cancer cells treated with oxaliplatin. Oncogene. 2010; 29: 48291.

3. Alderton GK, Bordon Y. Tumour immunotherapy-leukocytes take up the fight. Nat Rev Immunol. 2012; 12: 239.

4. Finn OJ. Molecular Origins of Cancer: Cancer Immunology. N Eng J Med. 2008; 358: 2704-15.

5. Yu H, Kortylewski M, Pardoll D. Crosstalk between cancer and immune cells: role of STAT3 in tumour microenvironment. Nat Rev Immunol. 2007; 7: 41-51.

6. Grivennikov SI, Greten FR, Karin M. Immunity, Inflammation, and Cancer. Cell. 2010; 140: 883-99.

7. Bromberg J, Wang TC. Inflammation and Cancer: IL-6 and STAT3 Complete the Link. Cancer Cell. 2009; 15: 79-80.

8. Bollrath J, Phesse TJ, von Burstin VA, Putoczki T, Bennecke $\mathrm{M}$, Bateman T, et al. gp130-mediated Stat3 activation in enterocytes regulates cell survival and cell-cycle progression during colitis-associated tumorigenesis. Cancer Cell. 2009; 15: 91-102.

9. Grivennikov S, Karin E, Terzic J, Mucida D, Yu GY, Vallabhapurapu S. IL-6 and STAT3 are required for survival of intestinal epithelial cells and development of colitis-associated cancer. Cancer Cell. 2009; 15: 103-13.

10. Jarnicki A, Putoczki T, Ernst M. Stat3: linking inflammation to epithelial cancer-more than a"gut" feeling?. Cell Division. 2010; 5: 1-15.

11. Bollrath J, Greten FR. IKK/NF-KB and STAT3 pathways: central signalling hubs in inflammation-mediated tumour promotion and metastasis. EMBO reports. 2009; 10: 1314-9.

12. Eiró N, Vizoso FJ. Inflammation and cancer. World J Gastrointest Surg. 2012; 4: 62-72.

13. Danese S, Mantovani A. Inflammatory bowel disease and intestinal cancer: a paradigm of the Yin-Yang interplay between inflammation and cancer. Oncogene. 2010; 29: 3313-23.

14. Mantovani A. Cancer-related inflammation: the seventh hallmark of cancer. American Society of Clinical Oncology. 2009; 1092-9118/09/1-10: 723-6.

15. Levy DE, Lee C. What does Stat3 do? J. Clin. Invest. 2002; 109: 1143-8.

16. Siddiquee KAZ, Turkson J. STAT3 as a target for inducing apoptosis in solid and hematological tumors. Cell Research. 2008; 18: 254-67.

17. Yu H, Pardoll D, Jove R. STATs in cancer inflammation and immunity: a leading role for STAT3. Nature Rev. Cancer. 2009; 9: 798-809.

18. Zitvogel L, Tesniere A, Kroemer G. Cancer despite immunosurveillance: immune-selection and immunosubversion. Nature Rev. Immunol. 2006; 6: 715-27.

19. Huang S. Regulation of Metastases by Signal Transducer and Activator of Transcription 3 Signaling Pathway: Clinical Implications. Clin Cancer Res. 2007; 13: 1362-6.

20. Hanahan D, Weinberg RA. The hallmarks of cancer. Cell. 2000; 100: 57-70.

21. Xiong $H$, Zhang ZG, Tian $X Q$, Sun DF, Liang $Q C$, Zhang YJ, et al. Inhibition of JAK1, 2/STAT3 Signaling Induces Apoptosis, Cell Cycle Arrest, and Reduces Tumor Cell Invasion in Colorectal Cancer Cells. Neoplasia. 2008; 10: 287-97.

22. Kujawski M, Kortylewski M, Lee $H$, Herrmann A, Kay $H$, $\mathrm{Yu} \mathrm{H}$. Stat3 mediates myeloid cell-dependent tumor angiogenesis in mice. J. Clin. Invest. 2008; 118: 3367-77.

23. Kalluri R, Weinberg RA. The basics of epithelial-mesenchymal transition. J. Clin. Invest. 2009; 119: 1420-8.

24. Joyce JA, Pollard JW. Microenvironmental regulation of metastasis. Nat. Rev. Cancer. 2009; 9: 239-52.

25. Polyak K, Weinberg RA. Transitions between epithelial and mesenchymal states: acquisition of malignant and stem cell traits. Nat. Rev. Cancer. 2009; 9: 265-73.

26. Lin L, Deangelis S, Foust E, Fuchs J, Li C, Li PK, et al. A novel small molecule inhibits STAT3 phosphorylation and DNA binding activity and exhibits potent growth suppressive activity in human cancer cells. Molecular Cancer. 2010; 9: 1-10. 